\title{
Comparative morphometric analysis of bloodstream and lymph forms of Trypanosoma (T.) brucei brucei grown in vitro and in vivo
}

\author{
H. HECKER AND R. BRUN \\ Swiss Tropical Institute, Socinstrasse 57, CH-4051 Basel, Switzerland
}

\begin{abstract}
Summary
The fine structure of bloodstream forms of Trypanosoma brucei cultivated in vitro, and of trypanosomes from lymph and blood of mammalian hosts, was compared morphometrically. The cell volume, quantitative parameters of the mitochondrion and of glycosomes were mainly investigated. A Coulter Channelyzer was used for the first time to measure the mean cell volume of living parasites. In vitro, the monomorphic trypanosomes between the feeder layer cells showed lower values for mitochondrial parameters than the slightly pleomorphic forms from the supernatant medium. Trypanosomes in culture were very similar morphologically to forms from lymph nodes of rats. Despite some morphometric differences between cultivated blood stream forms and those grown in vivo, the similarity of both populations was clear. Both populations, however, differed significantly from stages found in the vector or from procyclic culture forms.
\end{abstract}

\section{Introduction}

Bloodstream forms of pleomorphic, tsetse fly transmissible stocks of Trypanosoma (T.) brucei (including human pathogenic stocks) can be grown continuously in co-cultivation with fibroblast-like feeder layer cells in Minimum Essential Medium supplemented with $15 \%$ serum (BRUN et al., 1981). These investigators showed that several feeder layer/serum combinations supported continuous growth of bloodstream forms with retention of infectivity for mammalian hosts as well as for the tsetse fly (SCHONI et al., 1982). The surface coat, another characteristic feature of the mammalian stage, could also be demonstrated. Two different trypanosome populations were described from these cultures: one in the supernatant medium exhibiting slight pleomorphism and a second monomorphic one intercellularly between feeder layer cells resembling slender bloodstream forms.

The present study aimed to analyse quantitatively the ultrastructure of in vitro cultivated bloodstream forms in comparison to bloodstream and lymph forms from mammalian hosts and to find out if the difference observed between the two culture populations could be confirmed by stereological methods. In addition, we were interested to see how direct measurement of the cell volume, using a Coulter Channelyzer would compare to the indirect method previously employed, which is based on the measurement of nuclear volume from smears and the stereologically assessed nuclear-cytoplasmic volume ratio (HECKER et al., 1972).
Materials and Methods
Trypanosome stock
Trypanosoma brucei brucei STIB 247, a pleomorphic Trypanosoma brucei brucei STIB 247, a pleomorphic
tock which is readily transmitted by tsetse flies, was used for all experiments. This stock was isolated in the Serengeti National Park from a hartebeest (Alcelaphus buselaphus) and cryopreserved in liquid $\mathrm{N}_{2}$ after one rat passage.

\section{Culture system}

Bloodstream forms were grown in a system consisting of a feeder layer in Minimum Essential Medium (MEM) supplemented with $15 \%$ inactivated rabbit serum. The fibroblast-like cell line MEF was isolated from whole embryos of a vole, Microtus montanus. Isolation of the cell line, composition of the culture medium and maintenance of cultures were described elsewhere (BRUN et al., 1981). The rabbit serum was prepared in our laboratory from blood of New Zealand White rabbits.

Cultures were initiated by adding metacyclic forms obtained from infected tsctsc flies (Glossina $m$. morsitans) by salivation, to wells of 24-well tissue culture clusters containing a confluent MEF feeder layer and $1.0 \mathrm{ml}$ medium. The cultures were incubated at $36.5^{\circ} \mathrm{C}$ in $4 \% \mathrm{CO}_{2}-96 \%$ air in a humidified incubator.

\section{Isolation of trypanosomes from culture}

Trypanosomes growing in the supernatant medium were pelleted by centrifugation for $7 \mathrm{~min}$ at $1000 \mathrm{~g}$, resuspended in PSG buffer, $\mathrm{pH} 8$, and passed through a DEAE cellulose column (LANHAM, 1968). For the isolation of trypanosomes growing intercellularly the feeder layer had to be mechanically detached and the cells separated from one another by passing them several times through a Pasteur pipette. The tissue culture cells were allowed to settle and the supernatant, containing trypanosomes, was centrifuged for $7 \mathrm{~min}$ at $1000 \mathrm{~g}$. The pellet was resuspended in PSG and passed again through a DEAE cellulose column. The trypanosome suspension was subsequently used to make smears, for size distribution analysis and for electron microscopy.

\section{Isolation of trypanosomes from laboratory animals}

The mice used were female Swiss ICR (26-28 g) and the rats were female white SIV $(130 \mathrm{~g})$. Bloodstream forms from mice and rats were isolated from citrated blood taken from the heart of an ether anaesthetized animal. The blood was diluted with an equal volume of MEM and centrifuged for $15 \mathrm{~min}$ at $40 \mathrm{~g}$ to separate blood cells from trypanosomes. The supernatant was removed to another tube and the 
trypanosomes pelleted by centrifugation for $7 \mathrm{~min}$ at $1000 \mathrm{~g}$. The pellet was resuspended in PSG and the trypanosome suspension passed through a DEAE cellulose column.

Lymph forms were isolated from lymph nodes of infected rats. The lymph nodes were triturated in PSG with a loose-fitting teflon pestle. Cells and fragments of the lymph nodes were allowed to settle. The supernatant containing trypanosomes was further processed as above.

Size distribution analysis and determination of the mean cell volume

Size distribution analysis was carried out with a Coulter Counter ZBI (with a $100 \mu \mathrm{m}$ orifice and the settings $A=I=1 / 2$ ) in combination with a Coulter Channelyzer C-1000, setting the base channel threshold to 5 and the window width to 50 with EDIT on. For each channel the channel volume was multiplied by the number of trypanosomes, resulting in the total volume of the cells classified in the respective channel. From these numbers the mean cell volume $(\mathrm{Vc}) \pm$ standard error $(\mathrm{SE})$ of all trypanosomes in channels 4 to 61 could be calculated. About $8 \times 10^{4}$ cells were measured from each trypanosome population.

\section{Light microscopy}

Smears were prepared using approx. $10^{5}$ cells per sample. The trypanosomes were pelleted $(7 \mathrm{~min}$ at $1000 \mathrm{~g}$ ) in $2 \%$ bovine serum albumin in $M E M$ and smears prepared from the pellet. They were fixed either with methanol for 20 min or with $1 \%$ formalin in PSG for one hour and stained with Giemsa.

In addition to the direct measurement of the mean cell volume with the Coulter Channelyzer an indirect method was used for comparison. The nuclear volume was determined from Giemsa stained smears. Assuming the nuclei to be prolate ellipsoids, the long and short half axes of 50 to 100 nuclear profiles were measured per sample and the mean nuclear volume was calculated. From this value and the nuclear- cytoplasmic volume ratio the mean cytoplasmic volume as well as the mean cell volume could be calculated (BURRI \& HECKER, 1979).

\section{Electron microscopy}

Trypanosomes isolated from culture, or from blood or lymph nodes of laboratory animals were centrifuged for 7 Inin at $1000 \mathrm{~g}$ and the pellets resuspended in a small volume of $2 \% \mathrm{BSA}$ in MEM. This suspension was filled into capillary tubes, one end of which was sealed with plasticine, and centrifuged for $10 \mathrm{~min}$ at $1000 \mathrm{~g}$. The resulting pellets were fixed for $90 \mathrm{~min}$ in $2.5 \%$ glutaraldehyde- $0.1 \mathrm{M}$ cacodylate buffer $(\mathrm{pH}=7 \cdot 3)$ at $4^{\circ} \mathrm{C}$. They were then left overnight in cold $0 \cdot 2 \mathrm{M}$ cacodylate buffer with $5 \%$ sucrose and post-fixed for two hours in $2 \% \mathrm{OsO}_{4}-0.2 \mathrm{M}$ cacodylate buffer at $4^{\circ} \mathrm{C}$. The samples were block stained in $70 \%$ acetone containing $2 \%$ uranylacetate, dehydrated in acetone and propyleneoxide, and embedded in epon.

\section{Morphometry}

The mean quantitative composition of the trypanosomes was evaluated using stereological principles (BURRI \& HECKER, 1979; WEIBEL, 1979). For each sample 80 to 120 micrographs were used at a final magnification of $\sim 58000$ corresponding to about 420 $\mu^{2}$ of randomly sectioned trypanosomes. The volume of the flagellum was added to the cytoplasmic volume since the Coulter Channelyzer measured the total cell volume including the flagellum:

The following cellular parameters were investigated: the nuclear-cytoplasmic volume ratio ( $\mathrm{Vnu}$ / Vcy) and the volume density of the nucleus with respect to the cell volume $\left(V_{V_{n u, c}}\right)$. Other parameters were expressed with respect to the cytoplasmic vplume: the volume densities of the mitochondrion $\left.\mathrm{V}_{\mathrm{Vmi}, \mathrm{cy}}\right)$, of glycosomes $\left(\mathrm{V}_{\mathrm{V}_{\mathrm{gl}, \mathrm{cy}}}\right)$, of lipid inclusions ( $\left.V_{V l i, c y}\right)$ and the flagellum $\left(V_{V f l, c y}\right)$; the surface densities of the outer $\left(S_{V \text { mio,cy }}\right)$ and of the inner mitochondrial membranes ( $\left.S_{V m i, c y}\right)$.

From these parameters the following secondary

Table I-Relative morphometric parameters (means \pm standard errors) of $T$. brucei STIB 247

\begin{tabular}{|c|c|c|c|c|c|c|c|c|c|}
\hline & $\mathrm{V}_{\mathrm{Vmi}, \mathrm{cy}}$ & $\mathrm{S}_{\mathrm{Vmio}, \mathrm{cy}}$ & $\mathrm{S}_{\text {Vmii, cy }}$ & $(\mathrm{S} / \mathrm{V})$ mio & $(\mathrm{S} / \mathrm{V}) \mathrm{mii}$ & Smii/Smio & $\bar{V}_{\text {Vgly,cy }}$ & $\mathrm{V}_{\mathrm{Vli}, \mathrm{cy}}$ & $\overline{V_{\text {Vfl,cy }}}$ \\
\hline $\begin{array}{l}\text { culture } \\
\text { feeder layer }\end{array}$ & $\begin{array}{r}0.036 \\
\pm .003\end{array}$ & $\begin{array}{r}0.678 \\
\pm .045\end{array}$ & $\begin{array}{r}0.733 \\
\pm .051\end{array}$ & $\begin{array}{r}19 \cdot 3 \\
\pm \cdot 7\end{array}$ & $\begin{array}{r}20.8 \\
\pm .9\end{array}$ & $\begin{array}{r}1 \cdot 08 \\
\pm .02\end{array}$ & $\begin{array}{r}0.070 \\
\pm .006\end{array}$ & $\begin{array}{r}0.017 \\
\pm .002\end{array}$ & $\begin{array}{r}0.181 \\
\pm .008\end{array}$ \\
\hline $\begin{array}{l}\text { culture } \\
\text { supernatant }\end{array}$ & $\begin{array}{r}0.056 \\
\pm .005\end{array}$ & $\begin{array}{r}0.827 \\
\pm .049\end{array}$ & $\begin{array}{r}0.994 \\
\pm .063\end{array}$ & $\begin{array}{l}15 \cdot 5 \\
\pm \cdot 9\end{array}$ & $\begin{array}{r}18 \cdot 4 \\
\pm \cdot 9\end{array}$ & $\begin{array}{r}1 \cdot 20 \\
\pm \cdot 02\end{array}$ & $\begin{array}{r}0.070 \\
\pm .005\end{array}$ & $\begin{array}{r}0.025 \\
\pm .002\end{array}$ & $\begin{array}{r}0.127 \\
\pm .009\end{array}$ \\
\hline $\begin{array}{l}\text { blood } \\
\text { mouse }\end{array}$ & $\begin{array}{r}0.077 \\
\pm .006\end{array}$ & $\begin{array}{r}1 \cdot 048 \\
\pm \cdot 062\end{array}$ & $\begin{array}{r}1 \cdot 464 \\
\pm \cdot 090\end{array}$ & $\begin{array}{r}14 \cdot 0 \\
\pm \cdot 6\end{array}$ & $\begin{array}{r}19 \cdot 4 \\
\pm \cdot 7\end{array}$ & $\begin{array}{r}1 \cdot 40 \\
\pm \cdot 03\end{array}$ & $\begin{array}{r}0.051 \\
\pm .004\end{array}$ & $\begin{array}{r}0.028 \\
\pm .002\end{array}$ & $\begin{array}{r}0.145 \\
\pm .006\end{array}$ \\
\hline $\begin{array}{l}\text { blood } \\
\text { rat }\end{array}$ & $\begin{array}{r}0 \cdot 108 \\
\pm \cdot 010\end{array}$ & $\begin{array}{r}1 \cdot 146 \\
\pm \cdot 074\end{array}$ & $\begin{array}{r}2 \cdot 039 \\
\pm \cdot 179\end{array}$ & $\begin{array}{r}10 \cdot 9 \\
\pm \cdot 4\end{array}$ & $\begin{array}{l}19 \cdot 0 \\
\pm \cdot 3\end{array}$ & $\begin{array}{r}1 \cdot 76 \\
\pm \cdot 06\end{array}$ & $\begin{array}{r}0.046 \\
\pm .004\end{array}$ & $\begin{array}{r}0 \cdot 027 \\
\pm \cdot 003\end{array}$ & $\begin{array}{r}0.115 \\
\pm .005\end{array}$ \\
\hline $\begin{array}{l}\text { lymph } \\
\text { rat }\end{array}$ & $\begin{array}{r}0.046 \\
\pm .004\end{array}$ & $\begin{array}{r}0.839 \\
\pm .041\end{array}$ & $\begin{array}{r}0.898 \\
\pm .052\end{array}$ & $\begin{array}{r}18 \cdot 9 \\
\pm 1 \cdot 0\end{array}$ & $\begin{array}{r}20 \cdot 0 \\
\pm \cdot 8\end{array}$ & $\begin{array}{r}1 \cdot 07 \\
\pm .03\end{array}$ & $\begin{array}{r}0.067 \\
\pm .005\end{array}$ & $\begin{array}{r}0.010 \\
\pm \cdot 001\end{array}$ & $\begin{array}{r}0.166 \\
\pm .008\end{array}$ \\
\hline
\end{tabular}

$\overline{V_{V m i}, y}=$ volume density of mitochondrion $\left(\mu \mathrm{m}^{3} / \mu \mathrm{m}^{3}\right), S_{V_{\text {mio,cy }}}=$ surface density of mitochondrial outer membrane $\left(\mu \mathrm{m}^{2} / \mu \mathrm{m}^{3}\right), S_{V m i i, c y}=$ surface density of mitochondrial inner membrane, $(\mathrm{S} / \mathrm{V})$ mio $=$ ratio of the surface area of the outer membrane to the mitochondrial volume $\left(\mu \mathrm{m}^{2} / \mu \mathrm{m}^{3}\right),(\mathrm{S} / \mathrm{V}) \mathrm{mii}=$ ratio of the surface area of the inner membrane to the mitochondrial volume, Smii/Smio = ratio of the surface area of the inner to the outer mitochondrial membrane $\left(\mu \mathrm{m}^{2} / \mu \mathrm{m}^{2}\right), \mathrm{V}_{\mathrm{Vgly}, \mathrm{cy}}=$ volume density of glycosomes, $\mathrm{V}_{\mathrm{Vli}, \mathrm{cy}}=$ volume density of lipid inclusions, $V_{V f, c y}=$ volume density of the flagellum, cy = with respect to cytoplasmic volume, flagellum included. 
Table II-Morphometric parameters (means \pm standard errors) of $T$. brucei STIB 247

\begin{tabular}{|c|c|c|c|c|c|c|c|c|c|c|}
\hline & $\mathrm{Vc}^{1}$ & $V_{\text {Vnu,c }}$ & Vnu,c & Vcy,c & Vmi,c & Smio,c & Smii,c & Vgly,c & Vli,c & $\overline{V f l, c}$ \\
\hline $\begin{array}{l}\text { culture } \\
\text { feeder layer }\end{array}$ & $\begin{array}{r}18 \cdot 60 \\
\pm .02\end{array}$ & $\begin{array}{r}0.133 \\
\pm .012\end{array}$ & $\begin{array}{r}2 \cdot 5 \\
\pm \cdot 2\end{array}$ & $\begin{array}{c}16 \cdot 1 \\
\pm \cdot 2\end{array}$ & $\begin{array}{r}0.58 \\
\pm .05\end{array}$ & $\begin{array}{r}10.9 \\
\pm \quad 7\end{array}$ & $\begin{array}{r}11.8 \\
\pm .8\end{array}$ & $\begin{array}{r}1 \cdot 13 \\
\pm \cdot 10\end{array}$ & $\begin{array}{r}0 \cdot 27 \\
\pm \cdot 03\end{array}$ & $\begin{array}{r}2 \cdot 9 \\
\pm \cdot 1\end{array}$ \\
\hline $\begin{array}{l}\text { culture } \\
\text { supernate }\end{array}$ & $\begin{array}{r}19 \cdot 35 \\
\pm .03\end{array}$ & $\begin{array}{r}0.127 \\
\pm .015\end{array}$ & $\begin{array}{r}2 \cdot 5 \\
\pm \cdot 3\end{array}$ & $\begin{array}{r}16.9 \\
\pm .3\end{array}$ & $\begin{array}{r}0.95 \\
\pm .09\end{array}$ & $\begin{array}{r}14 \cdot 0 \\
\pm \quad 9\end{array}$ & $\begin{array}{r}16 \cdot 8 \\
\pm 1 \cdot 1\end{array}$ & $\begin{array}{r}1 \cdot 18 \\
\pm \cdot 09\end{array}$ & $\begin{array}{r}0.42 \\
\pm .04\end{array}$ & $\begin{array}{r}2 \cdot 2 \\
\pm \cdot 2\end{array}$ \\
\hline $\begin{array}{l}\text { blood } \\
\text { mouse }\end{array}$ & $\begin{array}{r}20 \cdot 40 \\
\pm \cdot 02\end{array}$ & $\begin{array}{r}0 \cdot 111 \\
\pm \cdot 010\end{array}$ & $\begin{array}{r}2 \cdot 3 \\
\pm \cdot 2\end{array}$ & $\begin{array}{l}18 \cdot 1 \\
\pm \cdot 2\end{array}$ & $\begin{array}{r}1 \cdot 43 \\
\pm \cdot 11\end{array}$ & $\begin{array}{r}19 \cdot 4 \\
\pm 1 \cdot 2\end{array}$ & $\begin{array}{r}27 \cdot 1 \\
\pm 1 \cdot 7\end{array}$ & $\begin{array}{r}0.94 \\
\pm .08\end{array}$ & $\begin{array}{r}0.52 \\
\pm .04\end{array}$ & $\begin{array}{r}2 \cdot 7 \\
\pm \cdot 1\end{array}$ \\
\hline $\begin{array}{l}\text { blood } \\
\text { rat }\end{array}$ & $\begin{array}{r}22 \cdot 89 \\
\pm \cdot 02\end{array}$ & $\begin{array}{r}0 \cdot 154 \\
\pm \cdot 013\end{array}$ & $\begin{array}{r}3 \cdot 5 \\
\pm \cdot 3\end{array}$ & $\begin{array}{r}19 \cdot 4 \\
\pm \cdot 3\end{array}$ & $\begin{array}{r}2 \cdot 10 \\
\pm \cdot 20\end{array}$ & $\begin{array}{r}22 \cdot 2 \\
\pm 1 \cdot 5\end{array}$ & $\begin{array}{r}39 \cdot 6 \\
\pm 3.5\end{array}$ & $\begin{array}{r}0.89 \\
\pm .08\end{array}$ & $\begin{array}{r}0.52 \\
\pm .06\end{array}$ & $\begin{array}{r}2 \cdot 2 \\
\pm \cdot 1\end{array}$ \\
\hline $\begin{array}{l}\text { lymph } \\
\text { rat }\end{array}$ & $\begin{array}{l}19.60 \\
\pm .02\end{array}$ & $\begin{array}{r}0.145 \\
\pm .014\end{array}$ & $\begin{array}{r}2 \cdot 8 \\
\pm \cdot 3\end{array}$ & $\begin{array}{l}16.8 \\
\pm .3\end{array}$ & $\begin{array}{r}0.77 \\
\pm .07\end{array}$ & $\begin{array}{r}14 \cdot 1 \\
\pm \quad 7\end{array}$ & $\begin{array}{r}15 \cdot 1 \\
\pm .9\end{array}$ & $\begin{array}{r}1 \cdot 13 \\
\pm \cdot 09\end{array}$ & $\begin{array}{r}0 \cdot 17 \\
\pm \cdot 02\end{array}$ & $\begin{array}{r}2 \cdot 8 \\
\pm \cdot 1\end{array}$ \\
\hline
\end{tabular}

Idetermined with a Coulter Channelyzer

$\mathrm{Vc}=$ absolute cell volume $\left(\mu \mathrm{m}^{3}\right),{ }^{\mathrm{V}} \mathrm{Vnu}, \mathrm{c}=$ volume density of nucleus $\left(\mu \mathrm{m}^{3} / \mu \mathrm{m}^{3}\right), \mathrm{Vnu}, \mathrm{c}=$ absolute volume of nucleus, $\mathrm{Vcy}, \mathrm{c}=$ absolute volume of cytoplasm, $\mathrm{Vmi}, \mathrm{c}=\mathrm{absolute}$ volume of mitochondrion, Smio,c $=$ absolute surface area of mitochondrial outer membrane $\left(\mu \mathrm{m}^{2}\right)$, Smii,c $=$ absolute surface area of mitochondrial inner membrane, Vgly, $\mathrm{c}=$ absolute volume of glycosomes, Vli, $\mathrm{c}=$ absolute volume of lipid inclusions, $\mathrm{Vfl}, \mathrm{c}=$ absolute volume of flagellum. $\mathrm{c}=$ with respect to cell volume, flagellum included.

Table III-Direct and indirect determination of mean cell volume, flagellum included ( \pm standard errors) of $T$. brucei STIB 247

\begin{tabular}{lcrr}
\hline & $\mathrm{Vc}$ & $\mathrm{Vc}^{\mathrm{f}}$ & $\mathrm{Vc}^{\mathrm{m}}$ \\
\hline culture & $18 \cdot 60$ & $26 \cdot 1$ & $22 \cdot 4$ \\
feeder layer & $\pm \cdot 02$ & $\pm 2 \cdot 7$ & $\pm 2 \cdot 4$ \\
culture & $19 \cdot 35$ & $26 \cdot 8$ & $21 \cdot 5$ \\
supernate & $\pm \cdot 03$ & $\pm 3 \cdot 4$ & $\pm 3 \cdot 2$
\end{tabular}

$\mathrm{Vc}=$ values from Coulter Channelyzer (direct measurement), $\mathrm{Vc}^{\mathrm{f}}=$ values derived from the nuclear volume of formalin fixed trypanosomes and from the nuclear cytoplasmic volume ratio, $\mathrm{Vc}^{\mathrm{m}}=$ values derived from the nuclear volume of methanol fixed trypanosomes.

Table IV-Pleomorphism and mean cell volume of the $T$. brucei STIB 247 populations examined

\begin{tabular}{lcccc}
\hline & Vcell $^{1}$ & \multicolumn{3}{c}{ pleomorphism \% } \\
\cline { 3 - 5 } & $\mu^{3}$ & slender & intermediate & stumpy \\
\hline $\begin{array}{l}\text { culture } \\
\text { feeder layer }\end{array}$ & 18.6 & 82 & 18 & 0 \\
$\begin{array}{l}\text { culture } \\
\text { supernate }\end{array}$ & 19.35 & 58 & 36 & 6 \\
$\begin{array}{l}\text { blood } \\
\text { mouse }\end{array}$ & 20.4 & 68 & 30 & 2 \\
$\begin{array}{l}\text { blood } \\
\text { rat }\end{array}$ & 22.9 & 17 & 36 & 47 \\
$\begin{array}{l}\text { lymph } \\
\text { rat }\end{array}$ & 19.6 & 37 & 63 & 0 \\
\hline
\end{tabular}

'determined with a Coulter Channelyzer

parameters were derived: the ratio of the surface area of the mitochondrial outer membrane to the mitochondrial volume, $(\mathrm{S} / \mathrm{V}) \mathrm{mio}$, the ratio of the surface area of the inner membrane to the mitochond- rial volume, $(\mathrm{S} / \mathrm{V}) \mathrm{mii}$, and the ratio of the surface areas of the inner to the outer mitochondrial membranes, Smii/Smio.

From the absolute cell volume $(\mathrm{Vc})$ and the volume density of the nucleus $\left(\mathrm{V}_{\mathrm{Vnu}, \mathrm{c}}\right)$, the absolute volume of the nucleus (Vnu,c), and in a second step the volume of the cytoplasm $(\mathrm{V} c y, \mathrm{c})$, could be calculated. Using Vcy, $c$ and relative cellular parameters absolute values per cell could be obtained: Vmi,c $=$ absolute volume of the mitochondrion, $\mathrm{Vgly}, \mathrm{c}=$ of the glycosomes, Vli, $\mathrm{c}=$ of the lipid inclusions, $\mathrm{Vfl}, \mathrm{c}=$ of the flagellum; Smio $=$ absolute surface area of the mitochondrial outer membrane, and $\mathrm{Smii}=$ of the mitochondrial inner membrane.

Parameters were calculated as means \pm SE. Results were compared statistically using Student's t-test with a significance limit of $2 \mathrm{P} \leqslant 0 \cdot 05$.

\section{Results}

The morphometric parameters are listed in Tables I to III. Only the functionally more relevant parameters are presented below.

Mean cell volume $(V c)$

The mean cell volume of trypanosome populations was determined for the first time with a Coulter Channelyzer (Fig. 1). Vc was represented by about $8 \times 10^{4}$ cells for each population, and therefore even slight differences hefween mean values were statistically significant (Table II). The highest Vc was measured for the bloodstream population from the rat which consisted of $17 \%$ slender forms and almost $50 \%$ stumpy forms (Table IV). The bloodstream population from the mouse with $68 \%$ slender and hardly any stumpy forms gave a significantly lower value. In general, Vc of bloodstream forms was higher than Vc of culture or lymph node forms.

In addition to the direct determination of $\mathrm{Vc}$ with the Coulter Channelyzer, an indirect method (BURRI \& HECKER, 1979) was employed using the nuclear volume as measured from smears and the nuclear cytoplasmic volume ratio. This indirect method gave higher values than the Channelyzer (Table III). 


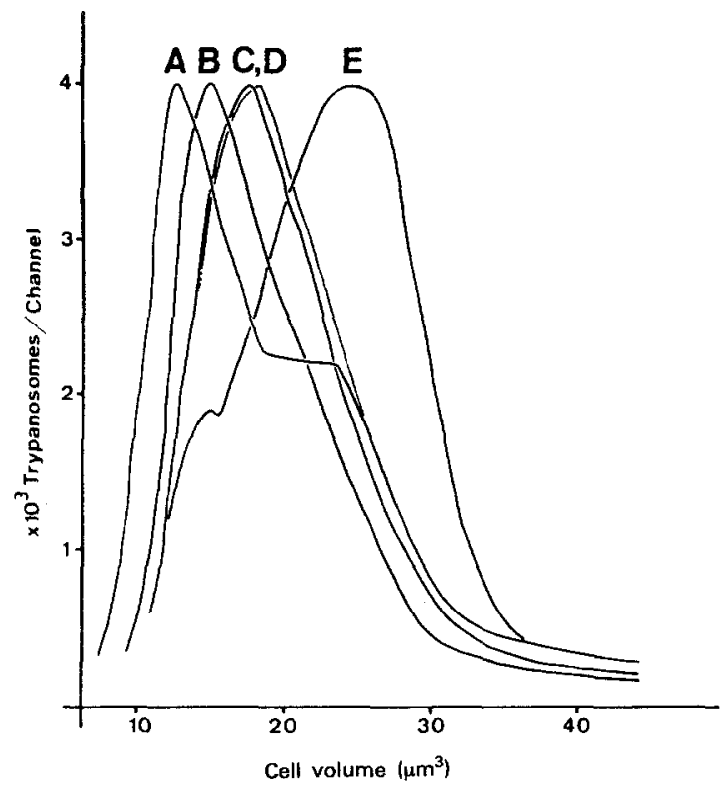

Fig. 1. Size distribution curves of $T$. brucei STIB 247 populations grown in vitro and in vivo. $\mathrm{A}=$ culture, supernatant population; $\mathrm{B}=$ culture, feeder layer population; $\mathrm{C}=$ rat lymph; $\mathbf{D}=$ mouse blood; $\mathbf{E}=$ rat blood.

However, the values obtained from methanol fixed smears were much closer to the Channelyzer results than were those obtained from formalin fixed smears.

\section{Mitochondrion}

The mean volume density, $V_{V_{m i}, c y}$ (Table I, Fig. 2) and the mean absolute volume of the mitochon-

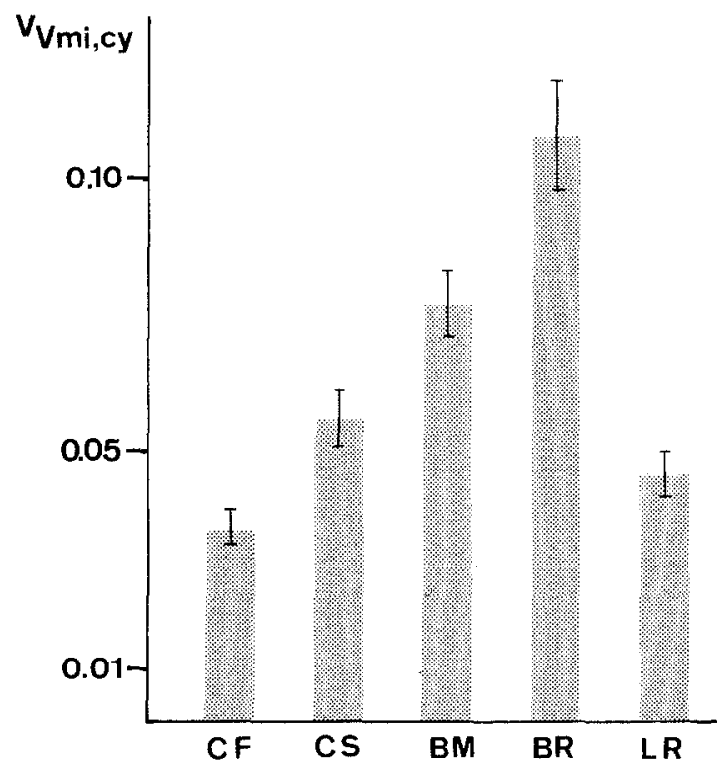

Fig. 2. Volume density of the mitochondrion (mean \pm standard error) of $T$ : brucei STIB 247 populations grown in vitro and in vivo. $\mathrm{CF}=$ culture, population between feeder layer cells; $\mathrm{CS}=$ culture, supernatant population; $\mathrm{BM}=$ blood of mouse, $\mathrm{BR}=$ blood of rat; $\mathrm{LR}=$ lymph of rat. drion, Vmi,c (Table II) were significantly higher in the rat blood (many stumpy forms, Table IV) as compared to the trypanosomes from mouse blood (mainly slender forms). The values for culture forms and forms from lymph nodes were significantly lower than those for bloodstream forms. With respect to culture forms, the pleomorphic forms in the supernatant medium contained more mitochondrion than the monomorphic trypanosomes located in the feeder layer. The surface densities and absolute surface areas of the outer and inner mitochondrial membranes were in accordance with the values of the mitochondrial volume.

The ratio of the surface of the outer mitochondrial membrane and the mitochondrial volume $(\mathrm{S} / \mathrm{V}) \mathrm{mio}$, (Table I) reflects to a certain extent the mean diameter and size of the organelle: the smaller this ratio the larger the mitochondrial profiles. The largest mitochondrion was found in the sample from rat blood, significantly smaller ones in mouse blood and in the supernatant of the culture. Trypanosomes isolated from the feeder layer and from lymph nodes contained the smallest mitochondrion. The morphometrically assessed ratio of the surface area of the inner membrane to the mitochondrial volume, $(\mathrm{S})$ V) mii, (T able I) is assumed to represent the ratio of enzymes of the respiratory chain to enzymes of the tricarboxylic acid cycle. This parameter proved to be similar for all the populations examined.

\section{Glycosomes}

Glycosomes are microbody-like, membrane bounded organelles which sometimes contain crystalloid inclusions (BÖHRINGER \& HECKER, 1975). Glycolytic enzymes which are involved in the trypanosomes' extramitochondrial respiration have been localized within this organelle (OPPERDOES \& BORST, 1977).

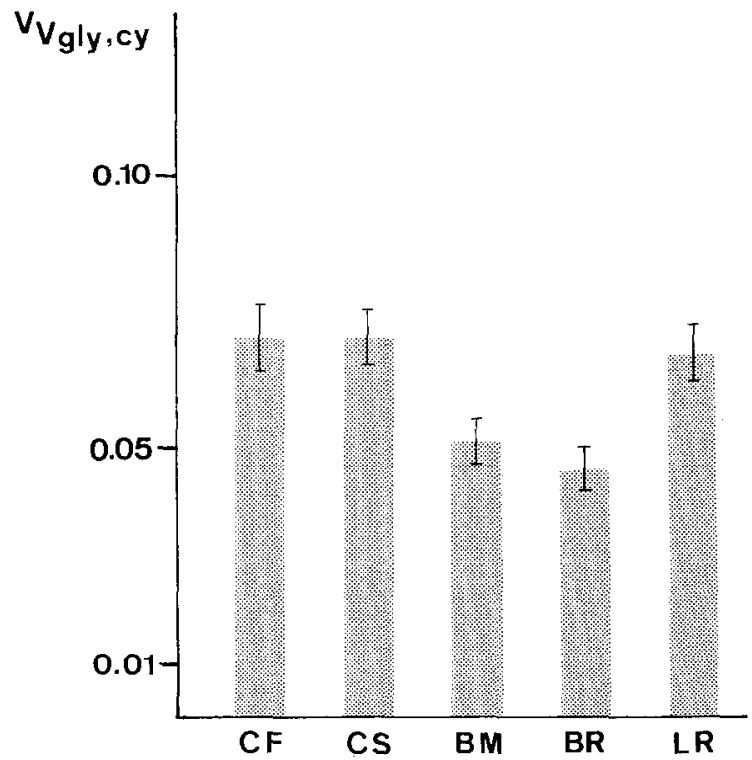

Fig. 3. Volume density of the glycosomes of $T$. brucei STIB 247 populations grown in vitro and in vivo. For explanations see Fig. 2. 
Volume densities, $V_{\text {Vgly,cy }}$ (Table I, Fig. 3) and absolute volumes of glycosomes, Vgly,c, did not differ significantly between culture forms and forms from lymph nodes, although bloodstream forms showed significantly lower values.

\section{Lipid inclusions}

Lipid inclusions were present in the form of strongly osmiophilic particles, but triglyceride-like inclusions could also be found (BÖHRINGER \& HECKER, 1975). Their total volume density, $V_{\text {Vil.cy, (Table }}$ I) and their absolute volume, Vli,c (Table II) were highest in bloodstream forms. Trypanosomes from culture showed a lower lipid content, especially the population between the feeder layer cells. The lowest lipid content was measured in lymph node forms.

\section{Discussion}

This study aimed to find out if bloodstream forms of $T$. brucei grown in vitro are similar to forms from the mammalian host with respect to their ultrastructural composition. The main cellular parameters used for this comparison were the cell volume, the mitochondrion and the glycosomes. BRUN et al. (1981) have shown that two trypanosome populations exist in a bloodstream form culture: one, which appears monomorphic and slender, between the feeder layer cells and a second one, slightly pleomorphic, in the supernatant medium. In the present investigation this observed difference was also expressed by the morphometric parameters of the mitochondrion, indicating that the two populations may also physiologically be slightly different. The few stumpy forms found in the supernatant were probably causing the difference in the mitochondrial values. This is, in addition to the light microscopical findings another indication that the stumpy forms in culture may be considered as 'real' stumpy forms.

The quantitative ultrastructural composition of trypanosomes from lymph nodes was very similar to the one of culture forms. Closer in all features than to that of the bloodstream forms from a mammalian host. These findings suggest that the trypanosomes in culture more probably represent tissue/lymph forms than simply bloodstream forms. In a previous investigation on lymph forms from the rat similar morphometric data were obtained (TANNER et al., 1980).

There were slight but statistically significant morphometric differences between bloodstream forms cultivated in vitro and those grown in vivo. These ultrastructural differences are presumably an expression of physiological dissimilarities. between the trypanosome populations. This is not surprising because the culture system is a very approximate substitution for the mammalian host, and adaptations to the conditions in vitro have to be expected. On the other hand we found distinct differences between our morphometric results for bloodstream forms grown in vitro and in vivo, compared to previously published data for procyclic forms of the various parasite stages in the vector. Procyclic culture forms are more than twice as large in volume, and all the mitochondrial parameters showed two to three times highes values (GHIOTTO et al., 1979). Comparison with forms in the midgut and the salivary glands of tsetse flies also revealed large differences (BÖHRINGER" \& HECKER, 1975; HECKER 1980). Because different trypanosome stocks were used in the investigations cited above, direct comparison with our results has to be made with caution.

The morphometrical examination of cultivated bloodstream forms clearly demonstrated that the trypanosomes in culture were morphologically very similar to forms from a mammalian host. The presence of a surface coat on cultivated bloodstream forms and their infectivity for mammalian hosts as well as for the vector Glossina m. morsitans have been demonstrated earlier (BRUN et al., 1981; SCHÖNI et al., 1982). There are also strong similarities in respiration (HILL et al., 1978; HILL, 1980), and, so far, no difference has been found between bloodstream forms from culture and from a mammalian host. Despite slight morphometrical differences between in vitro and in vivo bloodstream forms, the cultivated forms may really be regarded as mammalian stages. With some precautions they can be used for in vitro investigations replacing bloodstream forms from a mammalian host.

The mean cell volume of trypanosome populations was determined for the first time directly with a Coulter Channelyzer. The values were within a narrow range $\left(18.6\right.$ to $\left.22 \cdot 9 \mu^{3}\right)$ but still differed significantly from one another due to the large cell samples investigated. The size distribution curves (Fig. 1) showed the dissimilarities between samples much more clearly than did their mean volumes. The two trypanosome populations found in culture produced different size distribution curves although their mean cell volumes were closely similar. The monomorphic trypanosomes in the feeder layer gave one sharp peak, whereas the supernatant forms produced a curve with a peak and a shoulder which most probably represent the stumpy forms present in this sample. The curve for the bloodstream forms from the rat with almost $50 \%$ stumpy forms showed a broader peak shifted to the right. This indicated that the stumpy forms have a larger cell volume than the slender forms. However, the volume increase from slender to stumpy forms was less than $50 \%$. In earlier investigations using other $T$. brucei stocks an increase of the cell volume of about 2.5 times from slender to stumpy forms has been reported (HECKER, 1980, review). These volumes were determined by an indirect method (BURRI \& HECKER, 1979) which was also used in this work. For the two trypanosome populations in culture the cell volumes were determined with the Coulter Channelyzer and by the indirect method. For the latter method methanol and formalin fixed smears were used for the estimation of the mean nuclear volume. It became obvious that the fixation had a crucial influence on the nuclcar volumc. The values obtained from methanol fixed smears were closer to the directly measured cell volume than the ones obtained from formalin fixed preparations. The fact that the fixation of the smears had a significant effect on the preservation of the nucleus and thus on the estimation of the cell volume, suggests that the indirect method should be used with caution. For two of the stocks previously used to determine the cell volume indirectly, a direct measurement with the Coulter Channelyzer was done for slender and stumpy populations. We found that stumpy forms were slightly (but not more than $50 \%$ ) larger in volume than slender forms; for one stock the volume of 
slender and stumpy forms was almost identical (results not published). It therefore must be assumed that the indirect method overestimates the nuclear volume of stumpy forms.

\section{Acknowledgements}

The present investigation was supported in part by the Swiss National Foundation for Scientific Research, Grant Nr. 3.346-0.78. The authors gratefully acknowledge critical discussion of the manuscript by Dr. Leo Jenni and the skillful technical assistance by Erika Flury, Maja Hofmann and Margrit Schönenberger.

\section{References}

Böhringer, S. \& Hecker, H. (1975). Quantitative ultrastructural investigations of the life cycle of Trypanosoma brucei. A morphometric analysis. Foumal of Protozoology, 22, 463-467.

Brun, R., Jenni, L., Schönenberger, M. \& Schell, K.-F. (1981). In vitro cultivation of bloodstream forms of Trypanosoma brucei, $T$. rhodesiense and $T$. gambiense. Foumal of Protozoology, 28, 470-479.

Burri, P. H. \& Hecker, H. (1979). Stereological study of trypanosoma, a small protozoon. In: Stereological Methods, Volume 1. Weibel, E. R. (Editor). London: Academic Press, pp. 343-348.

Ghiotto, V., Brun, R., Jenni, L. \& Hecker, H. (1979). Trypanosoma brucei: morphometric changes and loss of infectivity during transformation of bloodstream forms to procyclic culture forms in vitro. Experimental Parasitology, 48, 447-456.

Hecker, H. (1980). Application of morphometry to pathogenic trypanosomes (Protozoa, Mastigophora). Pathology Research and Practice, 166, 203-217.
Hecker, H., Burri, P. H., Steiger, R. F. \& Geigy, R. (1972). Morphometric data on the ultrastructure of the pleomorphic bloodforms of Trypanosoma brucei. Acta Tropica, 29, 182-188.

Hill, G. C. (1980). Biochemical studies using Trypanosoma rhodesiense cultured-infective trypomastigotes. In: The host invader interplay. Van den Bossche, H. (Editor). Amsterdam: Elsevier/North Holland Biomedical Press, pp. 555-566.

Hill, G. C., Shimer, S., Caughey, B \& Sauer, S. (1978). Growth of infective forms of Trypanosoma $(T$.$) brucei on$ buffalo lung and Chinese hamster lung tissue culture cells. Acta Tropica, 35, 201-207.

Lanham, S. M. (1968). Separation of trypanosomes from blood of infected rats and mice by anion-exchangers. Nature, 218, 1273-1274.

Opperdoes, F. R. \& Borst, P. (1977). Localization of nine glycolytic enzymes in a microbody-like organelle in Trypanosoma brucei: The glycosome. FEBS Letters, 80, 360-364.

Schöni, R., Jenni, L. \& Brun, R. (1982). Cyclical transmission of in vitro cultivated bloodstream forms and procyclic trypomastigotes of Trypanosoma brucei brucei by Glossina morsitans morsitans. Zeitschrift für Parasitenkunde, (in press).

Tanner, M., Jenni, L., Hecker, H. \& Brun, R. (1980). Characterization of Trypanosoma brucei isolated from lymph nodes of rats. Parasitology, 80, 383-391.

Weibel, E. R. (1979). Stereological Methods, Volume 1, London: Academic Press.

Accepted for publication 26th March, 1982. 